\title{
Medication Belief and Adherence among Patients with Epilepsy
}

\author{
Yirga Legesse Niriayo $\mathbb{D}^{1},{ }^{1}$ Abraham Mamo, ${ }^{1}$ Kidu Gidey, ${ }^{1}$ and Gebre Teklemariam Demoz $\mathbb{D}^{2}$ \\ ${ }^{1}$ Department of Clinical Pharmacy, School of Pharmacy, College of Health Sciences, Mekelle University, Mekelle, Tigray, Ethiopia \\ ${ }^{2}$ Clinical Pharmacy and Pharmacy Practice Unit, Departments of Pharmacy, College of Health Sciences, Aksum University, Aksum, \\ Tigray, Ethiopia
}

Correspondence should be addressed to Yirga Legesse Niriayo; yirga.legesse@mu.edu.et

Received 6 December 2018; Accepted 17 March 2019; Published 23 April 2019

Academic Editor: József Janszky

Copyright ( 2019 Yirga Legesse Niriayo et al. This is an open access article distributed under the Creative Commons Attribution License, which permits unrestricted use, distribution, and reproduction in any medium, provided the original work is properly cited.

\begin{abstract}
Background. Medication adherence and belief are crucial to achieving the desired goal of therapy in epileptic patients. However, there is a lack of study regarding medication adherence and belief in our setting. Therefore, the purpose of this study was to investigate medication adherence and belief and associated factors among ambulatory patients with epilepsy. Method. A crosssectional study was conducted on randomly selected epileptic patients at the neurologic clinic of Ayder Comprehensive Specialized Hospital, Ethiopia. Medication adherence and belief were assessed using self-reported questionnaires which were developed based on the review of different literatures. Data were analyzed using binary logistic regression analysis. Result. We included a total of 292 patients. Almost two-thirds (65.4\%) of the patients were nonadherent to their medications. The most common cause of nonadherence was forgetfulness (48.7\%) followed by inability to get medicine (28.8) and safety concern (23.5\%). The majority (78.4\%) of the patients had high medication necessity belief while $44.1 \%$ had high concern belief about the potential adverse effect of their medications. Overall, 39.4\% of the patients had a negative belief toward their medications. Comorbidity (AOR: 3.51, 95\% CI: 1.20-10.31), seizure encounter within the last 3 months (AOR: 5.45, 95\% CI: 2.48-12.00), low medication necessity belief (AOR: 3.38, 95\% CI: 1.14-10.00), high medication concern belief (AOR: 4.23, 95\% CI: 2.07-8.63), and negative medication belief (AOR: 4.17, 95\% CI: 1.74-10.02) were predictors of medication nonadherence. Conclusion. Majority of the epileptic patients were nonadherent to their medications, and more than one-third of the patients had a negative medication belief. Low medication necessity belief, high medication concern belief, negative medication belief, comorbidity, and seizure encounter were predictors of medication nonadherence. Therefore, healthcare providers should design educational programs to enhance the patients' believe about their medication in order to improve medication adherence and overall treatment outcome.
\end{abstract}

\section{Introduction}

Epilepsy is the second most troublesome neurologic disorder worldwide in terms of disability-adjusted life years [1]. Epilepsy is a global public health problem that affects more than 70 million people worldwide [2], and more than $85 \%$ of the global burden of epilepsy occurs in developing countries [3, 4]. In Africa, epilepsy affected about 10 million people [5]. Ethiopia is also one of the highly affected countries in Africa with an estimated prevalence of 5.2/1000 population [6]. Epilepsy is a debilitating illness that leads to neuropsychological impairment, impairment of quality of life, frequent physical injury, social stigma, poor academic performance, reduced employment rate, and shortened lifetime [6-8].

Despite the availability of effective medications, there is a huge gap in the treatment of epilepsy in developing countries, particularly in Africa owing to the poor healthcare system, illiteracy, poor health awareness, and cultural unacceptance of modern medicine [4, 9-12]. In developing countries, epilepsy-associated stigma leads to higher treatment gaps, poor treatment outcomes, and reduced quality of life in epileptic patients [13]. In Africa, the majority of people still believe that epilepsy is caused by an evil spirit that cannot be effectively treated with modern medicine [5]. Antiepileptic 
drugs (AEDs) are the mainstay of therapy in the management of epilepsy and can achieve seizure freedom in $70 \%$ of patients if effective regimen is followed [14]. However, epilepsy remains uncontrolled in the majority of patients with epilepsy in developing countries [15]. Nonadherence remains the leading cause of treatment failure in epilepsy $[16,17]$.

Medication adherence is the extent to which patients take their medications as prescribed with respect to dosage and dosage intervals throughout the treatment period [18]. Despite medication adherence is a crucial part of patient care to achieve the desired goal of treatment, more than half of the patients are nonadherent to their prescribed medicines $[19,20]$. Studies have reported that the rate of adherence to AEDs ranges from 32 to $62 \%[16,21-23]$. Many factors including belief about medications, comorbidity, number of medications, duration of therapy, age, gender, and educational status have been associated with the rate of medication adherence $[22,23]$. Medication belief is the most important predictor of medication adherence, and it was significantly associated with medication adherence in different studies [24, 25]. Nonadherence to AED leads to poor seizure control, frequent hospital admissions, increased healthcare cost, impaired quality of life, and increased risk of mortality [17, 26, 27].

Assessment of medication adherence and belief and identification of factors affecting adherence to ADEs is important to improving overall epilepsy treatment outcome. However, there is a lack of study on medication adherence and belief and associated factors in our setting. Therefore, the aim of the current study was to (i) assess medication adherence and belief and (ii) evaluate the association of medication belief and other factors with medication adherence in patients with epilepsy.

\section{Material and Methods}

2.1. Study Design and Study Setting. A cross-sectional study was conducted between January 2017 and April 2017 at the neurologic clinic of Ayder Comprehensive Specialized Hospital which is located in northern Ethiopia. It is the second largest public hospital in Ethiopia that provides service for about 10 million people.

2.1.1. Study Population and Data Collection Procedure. Adult epileptic patients (age $\geq 18$ years), patients who were taking at least one AED, and those who had been on follow-up for at least six months were included in the study. Patients who were too ill to complete the interview, those who refused to give consent, and those with incomplete medical records were excluded from the study.

A sample of 304 was calculated using a single population proportion formula assuming $50 \%$ rate of medication adherence among patients with epilepsy, 95\% confidence level, 5\% margin of error, and $10 \%$ of contingency for nonresponse rate. From a total of 304 subjects approached, 12 patients were excluded from the study due to unwillingness to give consent [5], incomplete medical record [4], and serious illness to complete the interview [3].
We recruited patients into the study during their appointment for medication refilling using simple random sampling technique. Information related to sociodemographics, medication adherence, and belief was retrieved by interviewing patients using the standardized questionnaire. The clinical and treatment-related characteristics were retrieved from patients' medical record using the data abstraction checklist.

The Belief about Medicines Questionnaire (BMQ) was used to assess patients' belief about their medication [28]. BMQ is a self-reported questionnaire that encompasses two five-item scales evaluating the patients' belief about the necessity of their medications for controlling their disease and their concerns about the potential adverse effects of taking medications. According to BMQ, participants were said to have high medication necessity belief if the average sum of the five-item medication necessity scale score (ranging from 5-25) is above the midpoint; otherwise, they were considered to have low medication necessity belief. Similarly, participants were said to have high concern belief if the average sum of the five-item medication concern scale score (ranging from 5-25) is above the midpoint; otherwise, they were considered to have low medication concern belief. The overall patients' belief about their medication was determined by necessity concern differential, in which the patient's belief was considered as positive when the average sum of the 5-item patient's medication necessity scale score exceeded the average 5-item medication concerns scale; otherwise, it was considered as negative [29].

Medication adherence was assessed using a self-reported questionnaire which was developed based on the review of different literatures $[17,20,30,31]$. Patients were asked whether or not they missed or stopped a dose of their AED for any reason in the last month. We assessed adherence level in the last one-month period because of published literatures supporting the one-month recall period [17, 32, 33]. Accordingly, patients who took their AEDs appropriately according to the prescriber's instruction without missing or stopping a dose in the last month were said to be adherent, whereas patients who missed or stopped a dose of their AEDs within the last month were considered as nonadherent.

2.1.2. Data Analysis. Data were analyzed using the Statistical Package for the Social Sciences (SPSS version 21.0). We checked multicollinearity to test the correlation among predictor variables using the variance inflation factor (VIF), and none was collinear. Univariable logistic regression analysis was performed to determine the association of each independent variable with medication adherence, and a further multivariable binary logistic regression model was done to identify predictors of medication adherence. A $p$ value of $<0.05$ was considered statistically significant in all analyses.

2.1.3. Ethical Approval. This study was approved by the Ethics Review Committee of the School of Pharmacy, College of Health Sciences, Mekelle University. All study participants were well informed about the objective and protocol of the study. Written informed consent was obtained from all participants. Additionally, the privacy of personal information 
TABLE 1: Sociodemographic characteristics of epileptic patients $(n=292)$.

\begin{tabular}{|c|c|}
\hline Characteristics & $n(\%)$ \\
\hline \multicolumn{2}{|l|}{ Gender } \\
\hline Male & $179(61.3)$ \\
\hline Female & $113(38.7)$ \\
\hline \multicolumn{2}{|l|}{ Age in years } \\
\hline $18-30$ & $172(58.9)$ \\
\hline $31-60$ & $112(38.4)$ \\
\hline$>60$ & $8(2.7)$ \\
\hline \multicolumn{2}{|l|}{ Marital status } \\
\hline Married & $81(27.7)$ \\
\hline Single & $172(58.9)$ \\
\hline Divorce & $24(8.2)$ \\
\hline Widowed & $15(5.1)$ \\
\hline \multicolumn{2}{|l|}{ Residence } \\
\hline Rural & $156(53.4)$ \\
\hline Urban & $136(46.6)$ \\
\hline \multicolumn{2}{|l|}{ Educational level } \\
\hline Unable to write and read & $50(17.1)$ \\
\hline Primary school & $100(34.2)$ \\
\hline Secondary school & $124(42.5)$ \\
\hline Tertiary school & $18(6.2)$ \\
\hline \multicolumn{2}{|l|}{ Employment status } \\
\hline Employed & $27(27.9)$ \\
\hline Unemployed & $207(70.9)$ \\
\hline \multicolumn{2}{|l|}{ Social drug use } \\
\hline No & $250(85.6)$ \\
\hline Yes & $42(14.4)$ \\
\hline Monthly income & $315(92.7)$ \\
\hline$\leq 1500$ & $152(52.1)$ \\
\hline$>1500$ & $140(47.9)$ \\
\hline
\end{tabular}

was strictly preserved. All the methods were performed in accordance with approved institutional guidelines.

\section{Result}

3.1. Sociodemographic Characteristics. We included 292 patients in the final analysis of the study. Out of the total, $179(61.3 \%)$ were males and the mean $( \pm$ SD) age was $30.46 \pm 10.82$ years. More than half, 156 (53.4), were rural dwellers, and $14.4 \%$ were social drug users (Table 1).

3.2. Clinical and Treatment-Related Characteristics. Threefourths (75.7\%) of the participants had generalized epilepsy while $14.4 \%$ had focal epilepsy. Generalized tonic-clonic seizure (73.6\%) was the most common type of seizure, and 39\% of the patients had one or more comorbidities. Nearly twothirds $(61 \%)$ of the patients had been on treatment for five or more years, and $45.5 \%$ of the patients encountered seizure within the last 3 months. The most commonly prescribed AED was phenobarbitone (54.8\%) followed by phenytoin (52.1\%) (Table 2).
TABLE 2: Clinical and treatment-related characteristics of epileptic patients $(n=292)$.

\begin{tabular}{|c|c|}
\hline Characteristics & $n(\%)$ \\
\hline \multicolumn{2}{|l|}{ Comorbidity } \\
\hline No & $178(61.0)$ \\
\hline Yes & $114(39)$ \\
\hline \multicolumn{2}{|l|}{ Major comorbidities } \\
\hline Psychiatric disorder & $49(16.8)$ \\
\hline Migraine headache & $25(8.5)$ \\
\hline Cardiovascular disorder & $24(8.2)$ \\
\hline Respiratory disorders & $16(5.5)$ \\
\hline \multicolumn{2}{|l|}{ Type of epilepsy } \\
\hline Generalized epilepsy & $221(75.7)$ \\
\hline Focal epilepsy & $42(14.4)$ \\
\hline Unknown & $29(9.9)$ \\
\hline \multicolumn{2}{|l|}{ Type of seizure } \\
\hline GTC & $215(73.6)$ \\
\hline Focal seizure & $42(14.4)$ \\
\hline Absence seizure & $6(2.1)$ \\
\hline Unclassified seizure & $29(9.9)$ \\
\hline \multicolumn{2}{|l|}{ Duration of treatment } \\
\hline$<5$ & $114(39)$ \\
\hline$\geq 5$ & $178(61)$ \\
\hline \multicolumn{2}{|l|}{ Commonly used medications } \\
\hline Phenobarbitone & $160(54.8)$ \\
\hline Phenytoin & $152(52.1)$ \\
\hline Carbamazepine & $90(30.8)$ \\
\hline Valproate & $89(30.5)$ \\
\hline \multicolumn{2}{|c|}{ Seizure encounter in the last three months } \\
\hline No & $159(54.5)$ \\
\hline Yes & $133(45.5)$ \\
\hline \multicolumn{2}{|c|}{ Number of medicines per patient } \\
\hline$<3$ medication & $142(48.6)$ \\
\hline$\geq 3$ medication & $150(51.4)$ \\
\hline
\end{tabular}

3.3. Medication Belief of the Participants. More than threefourths (78.4\%) of the patients had high necessity belief about the importance of their medication for controlling their illness while $44.1 \%$ had high concern belief about the potential adverse effect of their medications. Overall, $60.6 \%$ had a positive perception toward their AEDs (Table 3).

In our study, two-thirds (65.4\%) of the patients were nonadherent to their AEDs. The most common cause for nonadherence was forgetfulness (48.7\%) followed by inability to get medicine (28.8), safety concern (23.5\%), and affordability problem (21.5\%) (Table 4$)$.

3.4. Factors Associated with Medication Adherence. Univariable logistic regression analysis was performed to compare adherent and nonadherent epileptic patients using the sociodemographic, medication belief, clinical, and treatment related characteristics. Accordingly, social drug use [crude odds ratio (COR): 2.21, 95\% CI: 1.02-4.82], comorbidity 
TABLE 3: Medication belief of the participants $(n=292)$.

\begin{tabular}{lc}
\hline Variables & $n(\%)$ \\
\hline Overall belief about medication & \\
$\quad$ Negative belief & $115(39.4)$ \\
Positive belief & $177(60.6)$ \\
Medication necessity belief & \\
$\quad$ High necessity belief & $229(78.4)$ \\
Low necessity belief & $63(21.6)$ \\
Medication concern belief & \\
High concern belief & $129(44.2)$ \\
Low concern belief & $163(55.8)$ \\
\hline
\end{tabular}

TABle 4: Adherence to AEDs and reasons for nonadherence $(n=292)$.

\begin{tabular}{lc}
\hline Characteristics & Number (\%) \\
\hline $\begin{array}{l}\text { Medication adherence } \\
\text { Adherent }\end{array}$ & $101(34.6)$ \\
Nonadherent & $191(65.4)$ \\
Reasons for nonadherence & \\
Forgetfulness & $93(48.7)$ \\
Inability to get medicine & $49(25.7)$ \\
Safety concern & $49(25.7)$ \\
Cost & $41(21.5)$ \\
Ran out of pills & $23(12)$ \\
Lack of hope & $16(8.4)$ \\
Not taking the medication during recovery & $16(8.4)$ \\
\hline
\end{tabular}

[COR: $5.60,95 \%$ CI: 3.06-10.25], number of medications $\geq 3$ [COR: $2.21,95 \%$ CI: $1.35-3.61$ ], seizure encounter within the last 3 months [COR: $11.44,95 \%$ CI: 5.96-21.96], low medication necessity belief [COR: 6.74, 95\% CI: 2.8-16.26], high medication concern belief [COR: 7.00, 95\%: 3.86-12.71], and negative medication belief [COR: 9.78, 95\% CI: 4.9219.46] were significantly associated with medication adherence (Table 5).

Variables with $p<0.2$ in the univariable analyses were included in the multivariable logistic regression model. The full model containing all predictors was statistically significant (chi-square $=137.207, \mathrm{df}=12, P<0.001)$. Comorbidity (AOR: 3.51, 95\% CI: 1.20-10.31), seizure encounter within the last 3 months (AOR: 5.45, 95\% CI: 2.48-12.00), low medication necessity belief (AOR: 3.38, 95\% CI: 1.14-10.00), high medication concern belief (AOR: 4.23, 95\% CI: 2.07-8.63), and negative medication belief (AOR: 4.17, 95\% CI: 1.7410.02) were found to be predictors of medication nonadherence (Table 5).

\section{Discussion}

Adherence to antiepileptic drugs is crucial to improving seizure control and overall treatment outcome in epileptic patients. However, maintaining good adherence to antiepileptic drugs remained the most important challenge in the globe, particularly in developing countries [18, 34]. Assessment of medication adherence and its contributing factors is helpful to designing programs for future intervention. Therefore, our study investigated the rate of nonadherence and its contributing factors among epileptic patients.

Studies have shown that most of the patients with epilepsy in developing countries are not treated or not appropriately treated $[11,35,36]$. In line with other similar studies $[22,23,37,38]$, majority $(65.4 \%)$ of the patients were nonadherent to their AED in our study. In contrast, the rate of adherence in our study was lower than those in studies done in China [39] and Germany [40]. The reason for this variance could be the poor perception of patients toward their illnesses and medication in developing countries including Ethiopia. In addition, it could be attributed to the difference in methods of adherence assessment.

Forgetfulness was the major reason for nonadherence in our study which is also supported by other similar studies $[22,38,41]$. Next to forgetfulness, the inability to obtain medication and safety concern were common causes of nonadherence. A similar finding was also reported in another similar study [21].

In our study, majority of patients had a positive belief about their medication which is comparable with a Saudi Arabian study [21]. Our study reported that majority of the patients had a high medication necessity belief about their AEDs while over one-third of the patients had high concern belief about the potential adverse effects of their medications which is similar with a United Kingdom study [25].

Medication belief was found to be an important predictor of medication adherence across different studies [24, 42]. Consistent with these studies, belief about medication was significantly associated with the rate of medication adherence in our study. In agreement to other studies [21, 25, 38, 43], patients with low necessity belief, high concern belief, and negative medication belief toward their AEDs were more likely to be nonadherent to their medications in this study. Therefore, more effort needs to be done to improve the awareness of patients about the importance of their medication in order to improve medication adherence.

In the present study, epileptic patients with comorbidity were less likely to be adherent to their medications which is also augmented by another similar study [22]. This could be explained that patients with comorbidity are more likely to have multiple drugs. Thus, they could be reluctant to take all drugs properly. Moreover, the risk of adverse drug events is increased in patients with comorbidities which can also negatively affect the adherence rate.

Several studies revealed that nonadherence to AEDs was significantly associated with poor seizure control $[16,17$, 44]. Likewise, patients with uncontrolled seizure were more likely to be nonadherent to their AEDs in the present study. This finding suggests that healthcare providers should design educational programs to enhance medication adherence so as to improve epilepsy treatment outcome.

Our study has some limitations. Our study may not provide adequate evidence regarding the cause-effect relationship of medication adherence and its risk factors due to the inherent characteristics of the cross-sectional study. In 
TABLE 5: Factors associated with medication adherence among epileptic patients $(n=292)$.

\begin{tabular}{|c|c|c|c|c|c|c|}
\hline \multirow{2}{*}{ Predictors } & \multicolumn{2}{|c|}{ Medication adherence } & \multirow{2}{*}{ COR (95\% CI) } & \multirow{2}{*}{$p$ value } & \multirow{2}{*}{ AOR (95\% CI) } & \multirow{2}{*}{$p$ value } \\
\hline & Adherent, $n(\%)$ & Nonadherent, $n(\%)$ & & & & \\
\hline \multicolumn{7}{|l|}{ Age in years } \\
\hline $18-30$ & $60(59.4)$ & $112(58.6)$ & 1 & 1 & 1 & 1 \\
\hline $31-60$ & $36(35.6)$ & $76(39.8)$ & $0.99(0.60-1.64)$ & 0.971 & $1.83(0.91-3.69)$ & 0.090 \\
\hline$>60$ & $5(5.0)$ & $3(1.6)$ & $0.305(0.07-1.32)$ & 0.113 & $0.62(0.07-5.55)$ & 0.671 \\
\hline \multicolumn{7}{|l|}{ Social drug use } \\
\hline No & $92(91.1)$ & $157(82.2)$ & 1 & 1 & 1 & 1 \\
\hline Yes & $9(8.9)$ & $34(17.8)$ & $2.21(1.02-4.82)$ & 0.045 & $0.79(0.26-2.40)$ & 0.672 \\
\hline \multicolumn{7}{|l|}{ Comorbidity } \\
\hline No & $85(84.2)$ & $93(48.7)$ & 1 & 1 & 1 & 1 \\
\hline Yes & $16(15.8)$ & $98(51.3)$ & $5.60(3.06-10.25)$ & $<0.001$ & $3.51(1.20-10.31)$ & 0.022 \\
\hline \multicolumn{7}{|l|}{ Types of seizure } \\
\hline GTC & $72(71.3)$ & $143(74.9)$ & 1 & 1 & 1 & 1 \\
\hline Focal seizure & $14(13.9)$ & $28(14.7)$ & $1.85(0.85-4.05)$ & 0.122 & $0.43(0.16-1.16)$ & 0.096 \\
\hline Absence seizure & $1(1.0)$ & $5(2.6)$ & $1.87(0.71-4.93)$ & 0.208 & $0.72(0.04-13.54)$ & 0.823 \\
\hline Unclassified seizure & $14(13.9)$ & $28(14.7)$ & $4.67(0.48-45.04)$ & 0.183 & $0.57(0.21-1.55)$ & 0.272 \\
\hline \multicolumn{7}{|l|}{ Number of medications } \\
\hline$<3$ & $62(61.4)$ & $80(41.9)$ & 1 & 1 & 1 & 1 \\
\hline$\geq 3$ & $39(38.6)$ & $111(58.1)$ & $2.21(1.35-3.61)$ & 0.002 & $0.53(0.21-1.36)$ & 0.185 \\
\hline \multicolumn{7}{|l|}{ Seizure encounter } \\
\hline No & $88(87.1)$ & $71(37.2)$ & & & & \\
\hline Yes & $13(12.9)$ & $120(62.8)$ & $11.44(5.96-21.96)$ & $<0.001$ & $5.45(2.48-12.00)$ & $<0.001$ \\
\hline \multicolumn{7}{|c|}{ Medication necessity belief } \\
\hline High necessity & $91(90.1)$ & $138(72.3)$ & 1 & 1 & 1 & 1 \\
\hline Low necessity & $10(9.9)$ & $53(27.7)$ & $6.74(2.80-16.26)$ & $<0.001$ & $3.38(1.14-10.00)$ & 0.028 \\
\hline \multicolumn{7}{|c|}{ Medication concern belief } \\
\hline Strong concern & $17(16.8)$ & $112(58.6)$ & $7.00(3.86-12.71)$ & $<0.001$ & $4.23(2.07-8.63)$ & $<0.001$ \\
\hline Low concern & $84(83.2)$ & $79(41.4)$ & 1 & 1 & 1 & 1 \\
\hline \multicolumn{7}{|c|}{ Over all medication belief } \\
\hline Negative belief & $11(10.9)$ & $104(54.5)$ & $9.78(4.92-19.46)$ & $<0.001$ & $4.17(1.74-10.02)$ & 0.001 \\
\hline Positive belief & $90(89.1)$ & $87(45.5)$ & 1 & 1 & 1 & 1 \\
\hline
\end{tabular}

COR: crude odds ratio; AOD: adjusted odds ratio; CI: confidence interval; GTC: generalized tonic seizure.

addition, as medication adherence and belief were assessed using self-reported data, patients may have underestimated these undesirable activities due to self-report concerns.

\section{Conclusion}

Majority of the epileptic patients were nonadherent to their medications, and forgetfulness was the common cause of nonadherence in this study. More than one-third of the patients had a negative belief about their medications. Low medication necessity belief, high medication concern belief, negative medication belief, comorbidity, and seizure encounter within the last 3 months were significantly associated with medication nonadherence. Therefore, healthcare providers should design educational programs to enhance the patients' belief about their medication in order to improve medication adherence and overall treatment outcome. Moreover, more emphasis should be given to patients with comorbidity and poor seizure control.

\section{Data Availability}

The dataset used to support the findings of this study is available from the corresponding author upon request.

\section{Conflicts of Interest}

The authors declare that they have no conflict of interest.

\section{Authors' Contributions}

YL conceptualized and designed the study, analyzed and interpreted the data, and drafted the original manuscript. $\mathrm{KK}, \mathrm{GT}$, and $\mathrm{AM}$ were involved in the supervision and 
manuscript evaluation. All authors have reviewed and approved the final version of the manuscript for submission.

\section{Acknowledgments}

We would like to acknowledge the data collectors and working staff members of Ayder Comprehensive Specialized Hospital for their impressive commitments and cooperation. Our gratefulness extended to the epileptic patients for their volunteer involvement in the study.

\section{References}

[1] K. M. Fiest, K. M. Sauro, S. Wiebe et al., "Prevalence and incidence of epilepsy: a systematic review and meta-analysis of international studies," Neurology, vol. 88, no. 3, pp. 296-303, 2017.

[2] A. Singh and S. Trevick, "The epidemiology of global epilepsy," Neurologic Clinics, vol. 34, no. 4, pp. 837-847, 2016.

[3] P. Song, Y. Liu, X. Yu et al., "Prevalence of epilepsy in China between 1990 and 2015: a systematic review and meta-analysis," Journal of Global Health, vol. 7, no. 2, article 020706, 2017.

[4] C. R. Newton and H. H. Garcia, "Epilepsy in poor regions of the world," The Lancet, vol. 380, no. 9848, pp. 1193-1201, 2012.

[5] J. Mugumbate and A. M. Zimba, "Epilepsy in Africa: past, present, and future," Epilepsy \& Behavior, vol. 79, pp. 239$241,2018$.

[6] T. Fanta, T. Azale, D. Assefa, and M. Getachew, "Prevalence and factors associated with perceived stigma among patients with epilepsy in Ethiopia," Psychiatry Journal, vol. 2015, Article ID 627345, 7 pages, 2015.

[7] K. D. Laxer, E. Trinka, L. J. Hirsch et al., "The consequences of refractory epilepsy and its treatment," Epilepsy \& Behavior, vol. 37, pp. 59-70, 2014.

[8] M. R. Sperling, "The consequences of uncontrolled epilepsy," CNS Spectrums, vol. 9, no. 2, pp. 98-109, 2004.

[9] C. K. Mbuba, A. K. Ngugi, C. R. Newton, and J. A. Carter, "The epilepsy treatment gap in developing countries: a systematic review of the magnitude, causes, and intervention strategies," Epilepsia, vol. 49, no. 9, pp. 1491-1503, 2008.

[10] M. B. Singh, "Epilepsy in developing countries: perspectives from India," Neurology, vol. 84, no. 15, pp. 1592-1594, 2015.

[11] E. Hunter, J. Rogathi, S. Chigudu et al., "The epilepsy treatment gap in rural Tanzania: a community-based study in adults," Seizure, vol. 36, pp. 49-56, 2016.

[12] A. Ba-Diop, B. Marin, M. Druet-Cabanac, E. B. Ngoungou, C. R. Newton, and P.-M. Preux, "Epidemiology, causes, and treatment of epilepsy in sub-Saharan Africa," The Lancet Neurology, vol. 13, no. 10, pp. 1029-1044, 2014.

[13] D. Sokhi, M. Diaz, A. Ngugi, T. Solomon, E. Fevre, and A.-C. Meyer, "Epilepsy prevalence, treatment gap, and stigma in Western Kenya (P1.272)," Neurology, vol. 86, 16 Supplement, 2016.

[14] V. D. Nunes, L. Sawyer, J. Neilson, G. Sarri, and J. H. Cross, "Diagnosis and management of the epilepsies in adults and children: summary of updated NICE guidance," BMJ, vol. 344, article e281, 2012.

[15] E. Perucca, "Treatment of epilepsy in developing countries," $B M J$, vol. 334, no. 7605, pp. 1175-1176, 2007.
[16] R. M. Jones, J. A. Butler, V. A. Thomas, R. C. Peveler, and M. Prevett, "Adherence to treatment in patients with epilepsy: associations with seizure control and illness beliefs," Seizure, vol. 15, no. 7, pp. 504-508, 2006.

[17] C. A. Hovinga, M. R. Asato, R. Manjunath et al., "Association of non-adherence to antiepileptic drugs and seizures, quality of life, and productivity: survey of patients with epilepsy and physicians," Epilepsy \& Behavior, vol. 13, no. 2, pp. 316-322, 2008.

[18] E. Sabaté, Adherence to Long-Term Therapies: Evidence for Action, World Health Organization, 2003.

[19] M. T. Brown and J. K. Bussell, "Medication adherence: WHO cares?," Mayo Clinic Proceedings, vol. 86, no. 4, pp. 304-314, 2011.

[20] W. Y. Lam and P. Fresco, "Medication adherence measures: an overview," BioMed Research International, vol. 2015, Article ID 217047, 12 pages, 2015.

[21] W. M. Gabr and M. E. E. Shams, "Adherence to medication among outpatient adolescents with epilepsy," Saudi Pharmaceutical Journal, vol. 23, no. 1, pp. 33-40, 2015.

[22] T. Y. Hasiso and T. A. Desse, "Adherence to treatment and factors affecting adherence of epileptic patients at Yirgalem General Hospital, Southern Ethiopia: a prospective crosssectional study," PLoS One, vol. 11, no. 9, article e0163040, 2016.

[23] C. M. M. Ferrari, R. M. C. de Sousa, and L. H. M. Castro, "Factors associated with treatment non-adherence in patients with epilepsy in Brazil," Seizure, vol. 22, no. 5, pp. 384-389, 2013.

[24] R. Horne, S. C. E. Chapman, R. Parham, N. Freemantle, A. Forbes, and V. Cooper, "Understanding patients' adherence-related beliefs about medicines prescribed for longterm conditions: a meta-analytic review of the NecessityConcerns Framework," PLoS One, vol. 8, no. 12, article e80633, 2013.

[25] S. C. E. Chapman, R. Horne, A. Chater, D. Hukins, and W. H. Smithson, "Patients' perspectives on antiepileptic medication: relationships between beliefs about medicines and adherence among patients with epilepsy in UK primary care," Epilepsy \& Behavior, vol. 31, pp. 312-320, 2014.

[26] G. O’Rourke and J. J. O’Brien, “Identifying the barriers to antiepileptic drug adherence among adults with epilepsy," Seizure, vol. 45, pp. 160-168, 2017.

[27] R. E. Faught, J. R. Weiner, A. Guérin, M. C. Cunnington, and M. S. Duh, "Impact of nonadherence to antiepileptic drugs on health care utilization and costs: findings from the RANSOM study," Epilepsia, vol. 50, no. 3, pp. 501509, 2009.

[28] R. Horne, J. Weinman, and M. Hankins, "The beliefs about medicines questionnaire: the development and evaluation of a new method for assessing the cognitive representation of medication," Psychology \& Health, vol. 14, no. 1, pp. 1-24, 1999.

[29] Y. L. Niriayo, K. Kumela, T. D. Kassa, and M. T. Angamo, "Drug therapy problems and contributing factors in the management of heart failure patients in Jimma University Specialized Hospital, Southwest Ethiopia," PLoS One, vol. 13, no. 10, article e0206120, 2018.

[30] L. Fialko, P. A. Garety, E. Kuipers et al., "A large-scale validation study of the Medication Adherence Rating Scale (MARS)," Schizophrenia Research, vol. 100, no. 1-3, pp. 5359, 2008. 
[31] K. Thompson, J. Kulkarni, and A. A. Sergejew, "Reliability and validity of a new Medication Adherence Rating Scale (MARS) for the psychoses," Schizophrenia Research, vol. 42, no. 3, pp. 241-247, 2000.

[32] P. Doro, R. Benko, A. Czako, M. Matuz, F. Thurzo, and G. Soos, "Optimal recall period in assessing the adherence to antihypertensive therapy: a pilot study," International Journal of Clinical Pharmacy, vol. 33, no. 4, pp. 690-695, 2011.

[33] J. Doughty, G. A. Baker, A. Jacoby, and V. Lavaud, "Compliance and satisfaction with switching from an immediaterelease to sustained-release formulation of valproate in people with epilepsy," Epilepsy \& Behavior, vol. 4, no. 6, pp. 710-716, 2003.

[34] R. A. Scott, S. D. Lhatoo, and J. W. Sander, "The treatment of epilepsy in developing countries: where do we go from here?," Bulletin of the World Health Organization, vol. 79, no. 4, pp. 344-351, 2001.

[35] A.-C. Meyer, T. Dua, J. Ma, S. Saxena, and G. Birbeck, "Global disparities in the epilepsy treatment gap: a systematic review," Bulletin of the World Health Organization, vol. 88, no. 4, pp. 260-266, 2010.

[36] G. L. Birbeck, "Epilepsy care in developing countries: part I of II," Epilepsy Currents, vol. 10, no. 4, pp. 75-79, 2010.

[37] W. M. Sweileh, M. S. Ihbesheh, I. S. Jarar et al., "Self-reported medication adherence and treatment satisfaction in patients with epilepsy," Epilepsy \& Behavior, vol. 21, no. 3, pp. 301305, 2011.

[38] L. Nakhutina, J. S. Gonzalez, S. A. Margolis, A. Spada, and A. Grant, "Adherence to antiepileptic drugs and beliefs about medication among predominantly ethnic minority patients with epilepsy," Epilepsy \& Behavior, vol. 22, no. 3, pp. 584586, 2011.

[39] J. Liu, Z. Liu, H. Ding, and X. Yang, “Adherence to treatment and influencing factors in a sample of Chinese epilepsy patients," Epileptic Disorders, vol. 15, no. 3, pp. 289-294, 2013.

[40] S. Gollwitzer, K. Kostev, M. Hagge, J. Lang, W. Graf, and H. M. Hamer, "Nonadherence to antiepileptic drugs in Germany: a retrospective, population-based study," Neurology, vol. 87, no. 5, pp. 466-472, 2016.

[41] G. Kassahun, G. Moges, and Y. Demessie, "Assessment of patients' adherence to antiepileptic medications at Dessie Referral Hospital, chronic follow-up, South Wollo, Amhara Region, North East Ethiopia," Neurology Research International, vol. 2018, Article ID 5109615, 6 pages, 2018.

[42] B. Schüz, C. Marx, S. Wurm et al., "Medication beliefs predict medication adherence in older adults with multiple illnesses," Journal of Psychosomatic Research, vol. 70, no. 2, pp. 179187, 2011.

[43] A. Verma, K. Kiran, and A. Kumar, "Belief in medication and adherence to antiepileptic drugs in people with epilepsy: a cross-sectional study from rural India," International Journal of Neuroscience, vol. 128, no. 12, pp. 1168-1173, 2018.

[44] G. M. Tefera, T. E. Woldehaimanot, and M. T. Angamo, "Poor treatment outcomes and associated factors among epileptic patients at Ambo Hospital, Ethiopia," Gaziantep Medical Journal, vol. 21, no. 1, pp. 9-16, 2015. 


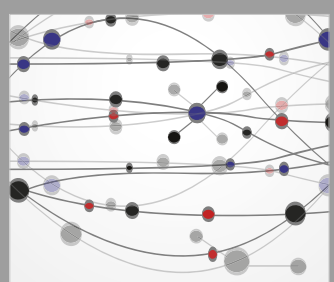

The Scientific World Journal
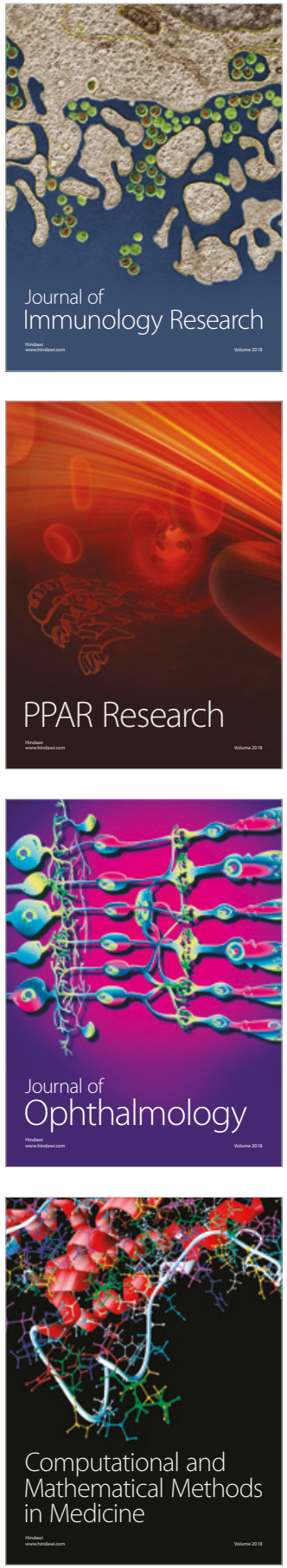

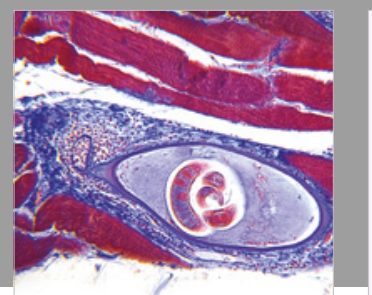

Gastroenterology Research and Practice

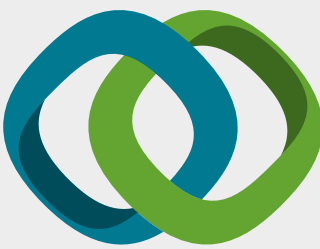

\section{Hindawi}

Submit your manuscripts at

www.hindawi.com
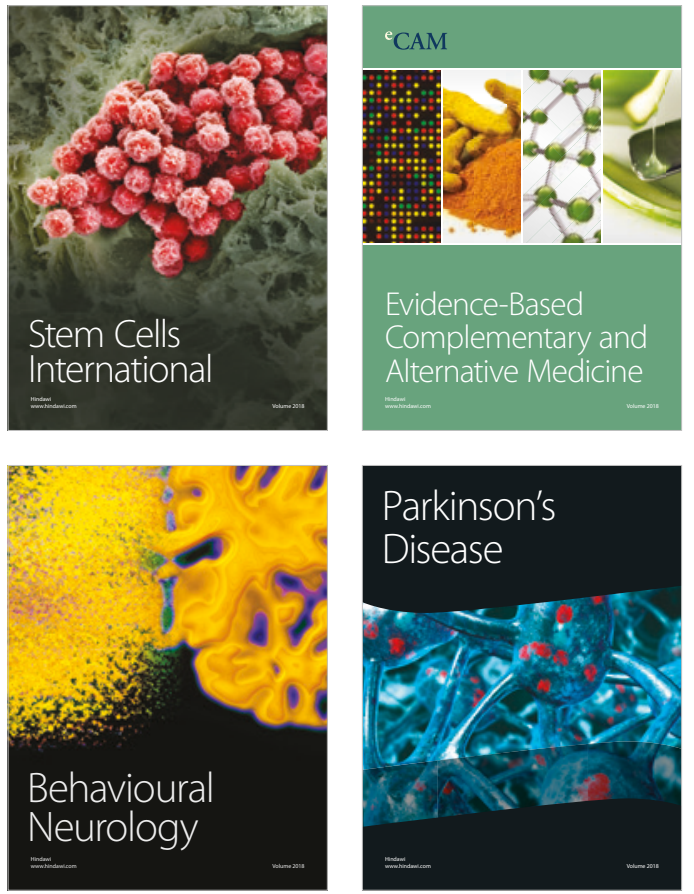

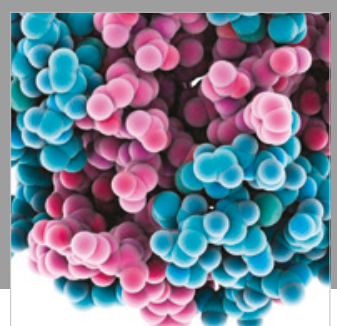

ournal of

Diabetes Research

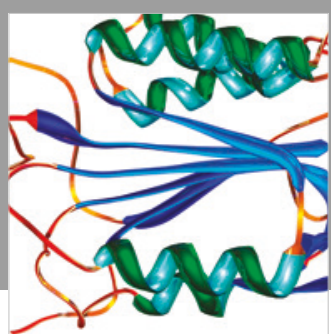

Disease Markers
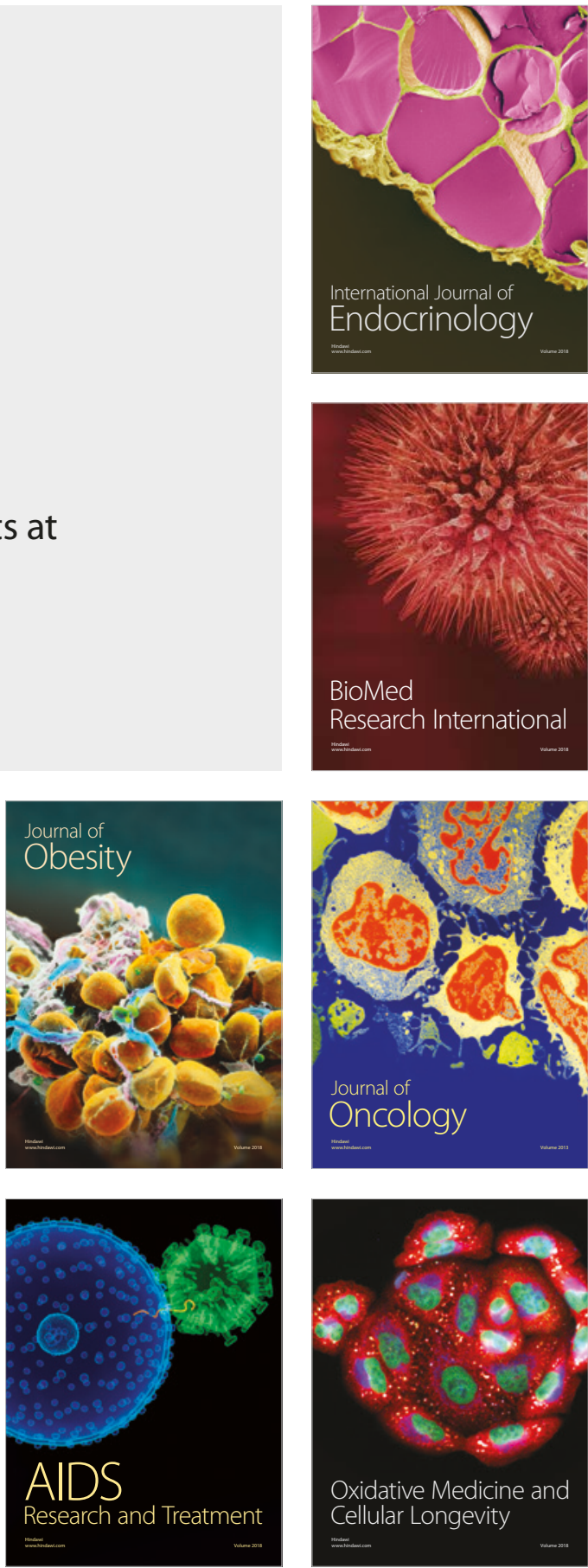